\title{
Hydraulic Jump in the Gulf of California
}

\author{
David Salas-Monreal ${ }^{1}$, David Alberto Salas-de-Leon ${ }^{2}$, María Adela Monreal-Gomez $^{2}$, \\ Mayra Lorena Riverón-Enzástiga ${ }^{3}$, Erika Mojica-Ramírez ${ }^{3}$ \\ ${ }^{1}$ Instituto de Ciencias Marinas y Pesquerias, Universidad Veracruzana, Veracruz, Mexico \\ ${ }^{2}$ Instituto de Ciencias del Mar y Limnología, Mexico City, Mexico \\ ${ }^{3}$ Posgrado en Ciencias del Mar y Limnología, Mexico City, Mexico \\ Email: davsalas@uv.mx
}

Received June 8, 2012; revised July 3, 2012; accepted August 1, 2012

\begin{abstract}
Acoustic Doppler current profiles and water density profiles were measured over the $280 \mathrm{~m}$ deep continental slope of the Gulf of California to elucidate the bathymetric effect on zooplankton distribution. These measurements were combined with water velocity and density simulations from the Regional Ocean Model System with and without the influence of Coriolis acceleration. The data revealed an acceleration of the near-bottom flow as it moved toward increasing depths. This acceleration was produced by the adjustment of the isopycnals to bathymetry (hydraulic jump). Zooplankton patches moved downward at the continental slope and then upward, thus exhibiting wave patterns. Model outputs without the effect of Coriolis acceleration also suggested that vertical zooplankton concentration followed a wave pattern. However, when Coriolis acceleration was added to the momentum equation, the horizontal zooplankton distribution was enhanced, which reduced the vertical zooplankton concentration observed over irregular bathymetries. Coriolis acceleration was responsible for horizontal dispersal of up to $20 \%$ of the total zooplankton concentration located over the wave trough.
\end{abstract}

Keywords: Hydraulic Jump; Acoustic Doppler Current Profiles; Internal Waves; Zooplankton Biovolumes; Gulf of California

\section{Introduction}

An understanding of the stratified flow dynamics over irregular bathymetries is crucial for predicting flow patterns [1], lee wave generation [2], and their interactions with planktonic and organic matter concentration [3-7]. Such interactions depend on the degree of stratification and on the strength of tidal forcing [8]. Internal waves generated over irregular bathymetries explain part of the temperature and salinity variations observed in the water column [2]. Therefore, the vertical variation of the pycnocline, where most particulate and dissolved organic matter are concentrated [9], could be related to irregular bathymetries such as the continental slope [10], submarine canyons [7], and seamounts [11].

Increased vertical and horizontal nutrient flux occurs in areas with abrupt bathymetric changes where internal waves break and produce mixing and increase primary productivity. For example, in Monterey Bay, one-third of the planktonic production was associated with amplified internal wave activity caused by the bathymetry of the Monterey Canyon [12]. Vertical and horizontal water exchange in areas with abrupt bathymetric changes is also attributed to shear instability [13]. The vertical displacement of high-nutrient deep-water enhanced by internal wave activity has a major ecological impact in adjacent waters $[14,15]$. Therefore, an understanding of current velocities and vertical water density variations induced by internal wave activity is crucial to describe near-surface concentration of planktonic organisms, nutrients, and detritus.

The amplification of internal waves over the continental slope are not commonly observed, therefore numerical models have described the near-surface concentration of organisms over internal wave troughs [16]. The nearsurface distribution of planktonic organism over bathymetric changes is usually assumed to be related to cyclonic eddies, nutrients, light penetration, and amplified internal wave activity [17]. However, the asymmetry of the water mass exchange is attributed to Coriolis acceleration [18]. The goal of this study is to advance our understanding of the distribution of zooplankton and its dependence on amplified internal wave activity induced by bathymetric changes such as the continental slope, under the influence of Coriolis acceleration.

\section{Data Collection and Processing}

\subsection{Data Collection}

Current profiles and backscatter intensity data from an 
acoustic Doppler current profiler (ADCP) were obtained over the $280 \mathrm{~m}$ deep continental slope of the Gulf of California to elucidate the effect of bathymetric depression on zooplankton concentration. The along-transect bathymetry over the continental slope was measured with an EA600 echo-sounder, which was also used to observe zooplankton concentration [19]. Those data come from an 11 days cruise performed on the western Gulf of California. However, this paper is mainly focus on the data collected on February 27, 2006 near a canyon located in the Gulf of California close to Carmen Island (Figure 1) when a hydraulic jump was observed. The hydraulic jump was detected using the ratio of the horizontal advective acceleration term versus the bottom friction term and the Froude number [20]. The transect was oriented with the axis of maximum standard deviation (principal axis) of tidal currents [18] in order to emphasize the velocity structure over the continental slope. During transect sampling, current velocity profiles and backscatter were recorded with a $150-\mathrm{kHz}$ vessel-mounted ADCP. The ADCP ping rate of $1 \mathrm{~Hz}$ was averaged every $5 \mathrm{~s}$, yielding a horizontal resolution of approximately 25 $\mathrm{m}$ and a vertical resolution of $5 \mathrm{~m}$. The ADCP compass was calibrated using a global positioning system data set following Trump and Marmorino [21].

The density profiles were obtained from a conductivitytemperature-depth (CTD of the Niel Brown company, version IV) along transect A-B (Figure 1). The concentration of zooplankton within the water column was estimated using an echo-sounder operating at a single frequency $(32 \mathrm{kHz})$ combined with backscatter outputs from the 150-kHz ADCP. Both the echo-sounder and the ADCP were mounted on the Research Vessel "El Puma" from the National Autonomous University of Mexico.

In addition, a time series of velocity data was recorded on February 27, 2006 to observe the tidal phase when lee waves were observed over the continental slope. The station was located over the continental slope (@ station in Figure 1) $\left(111.038^{\circ} \mathrm{W} ; 25.846^{\circ} \mathrm{N}\right)$. To emphasize the velocity structure over the bathymetric slope, the timeseries velocity data were modified by rotating the calibrated velocities to the angle of their maximum standard deviation [20].

To determine the relative abundance of the major zooplankton groups and to calibrate the acoustic-scattering data, double oblique tows of paired $60 \mathrm{~cm}$ mouth diameter Bongo nets fitted with 333 and $505 \mu \mathrm{m}$ mesh and calibrated flow meters were made for 15 minutes. Tows were conducted from a maximum depth of $200 \mathrm{~m}$ or from near the bottom in shallower zones to the surface at a speed of 2 knots $\left(1 \mathrm{~m} \cdot \mathrm{s}^{-1}\right)$. Tows were conducted at 48 zooplankton data point along the 11 days cruise. The zooplankton samples were fixed in a $4 \%$ formaldehyde in seawater solution and preserved with $70 \%$ alcohol. The

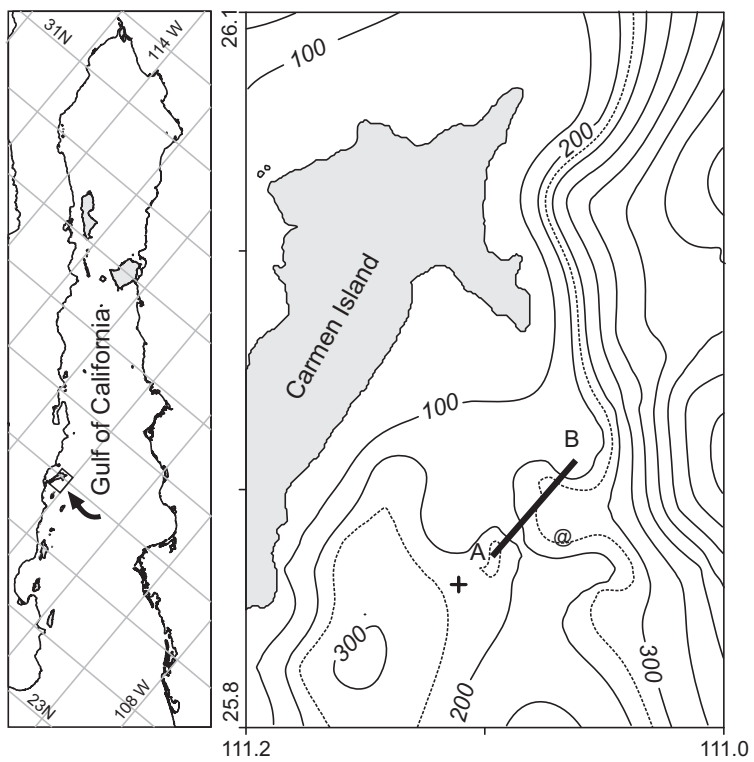

Figure 1. EA600 echo-sounder and 150-kHz ADCP measurements were taken along the $A-B$ transect in the Carmen Basin in the Gulf of California. The ADCP data series was conducted at $@$ and the CTD profile station is indicated by + .

samples were fractioned and analyzed in 1/32 and 1/8 subsamples for samples with high and low content of zooplankton, respectively [22]. The organisms were identified following Tregouboff and Rose [23].

\subsection{Model Setup}

Robertson [24] used the Regional Ocean Model System (ROMS) to model internal tides and to estimate tidal fields for studying circulation and mixing. This model showed good agreement with observations of semidiurnal baroclinic tides. However, the diurnal $\mathrm{K}_{1}$ baroclinic tides were poorly simulated. Robertson [24] found that a resolution of $4 \mathrm{~km}$ was sufficient for a qualitative estimate; whereas a resolution of $1 \mathrm{~km}$ reproduced most accurately the major axes and mean velocities of the semidiurnal baroclinic tides. These results illustrate that the ROMS model can reproduce the major features of barotropic and baroclinic tidal currents.

Our model was set up following Shchepetkin and McWilliams [25] and Moore et al. [26]. The outputs were used to describe the dynamics of an idealized generic system similar to the one located near Carmen Island. The three-dimensional primitive equations ocean model [26] uses $\sigma$ coordinates to increase the vertical resolution at the depth of the internal wave. The model simulates a $250 \mathrm{~m}$ depth slope with a horizontal domain of $2 \times 2 \mathrm{~km}$ alongshore and offshore, with 10 vertical levels and a horizontal resolution of $125 \mathrm{~m}$. The free surface elevation, which uses a non-gradient open boundary condition and the salinity, temperature, and water veloci- 
ties at each grid point were recorded over a 6 day period after the model reached stability. Bottom stress was assumed to be a quadratic function of the bottom velocity with a drag coefficient of $2.5 \times 10^{-3}$ [27]. The model started from a steady state with a uniform horizontal salinity and temperature field and a vertical step stratification of $1024 \mathrm{~kg} \cdot \mathrm{m}^{-3}$ at surface and $1027 \mathrm{~kg} \cdot \mathrm{m}^{-3}$ at the bottom. The boundary conditions were obtained using data from the ADCP (square transect performed around the study area) and with tidal amplitude and phase obtained from Salas-de-Leon et al. [18] and Carbajal and Backhaus [28]. The potential and kinetic energy were calculated for each grid point. The stability of the model was analyzed using the potential and kinetic energy. Once differences in energies from successive iterations were on the order of $10^{-3}$ or lower, the model was considered to be stable; this occurred after 4 days of simulations. The simulations were run with and without consideration of the Earth's rotational effects in the momentum equation in order to elucidate the relevance of Coriolis acceleration in the continental slope dynamics and zooplankton concentration. Although the ROMS is a hydrostatic model [29], the velocities obtained here were used to compare the inertial versus gravitational forces (Froude number).

The model does not account directly for zooplankton or detritus concentration because it does not contain any type of ecosystem model. However, it is assumed that over irregular bathymetries, planktonic organisms and detritus are concentrated at the pycnocline depth [3].

Although planktonic organisms are biologically active, there are similarities between the diffusion of salinity and the plankton advection [11]. Therefore, an analysis of the salinity field was used as an approximation to describe zooplankton distribution at the pycnocline depth. This analysis was validated with observations from the EA 600 echo-sounder and the ADCP (Figure 2(a)), where zooplankton concentrations were related to high values of backscatter intensity of the ADCP and the EA 600 echo-sounder signal within the area studied.

The Reynods averaged Navier-Stokes equations used in the model are:

$$
\begin{aligned}
& \frac{\partial Z u}{\partial t}+\frac{\partial u Z u}{\partial x}+v \frac{\partial v Z u}{\partial y}+\frac{\partial w Z u}{\partial \sigma}-f Z v \\
& =-\frac{Z}{\rho_{0}} \frac{\partial P}{\partial x}-Z g \frac{\partial \zeta}{\partial x}-\frac{\partial}{\partial \sigma}\left(\overline{u^{\prime} w^{\prime}}-\frac{v}{Z} \frac{\partial u}{\partial \sigma}\right) \\
& \frac{\partial Z v}{\partial t}+\frac{\partial u Z v}{\partial x}+v \frac{\partial v Z v}{\partial y}+\frac{\partial w Z v}{\partial \sigma}+f Z u \\
& =-\frac{Z}{\rho_{0}} \frac{\partial P}{\partial y}-Z g \frac{\partial \zeta}{\partial y}-\frac{\partial}{\partial \sigma}\left(\overline{u^{\prime} w^{\prime}}-\frac{v}{Z} \frac{\partial v}{\partial \sigma}\right)
\end{aligned}
$$

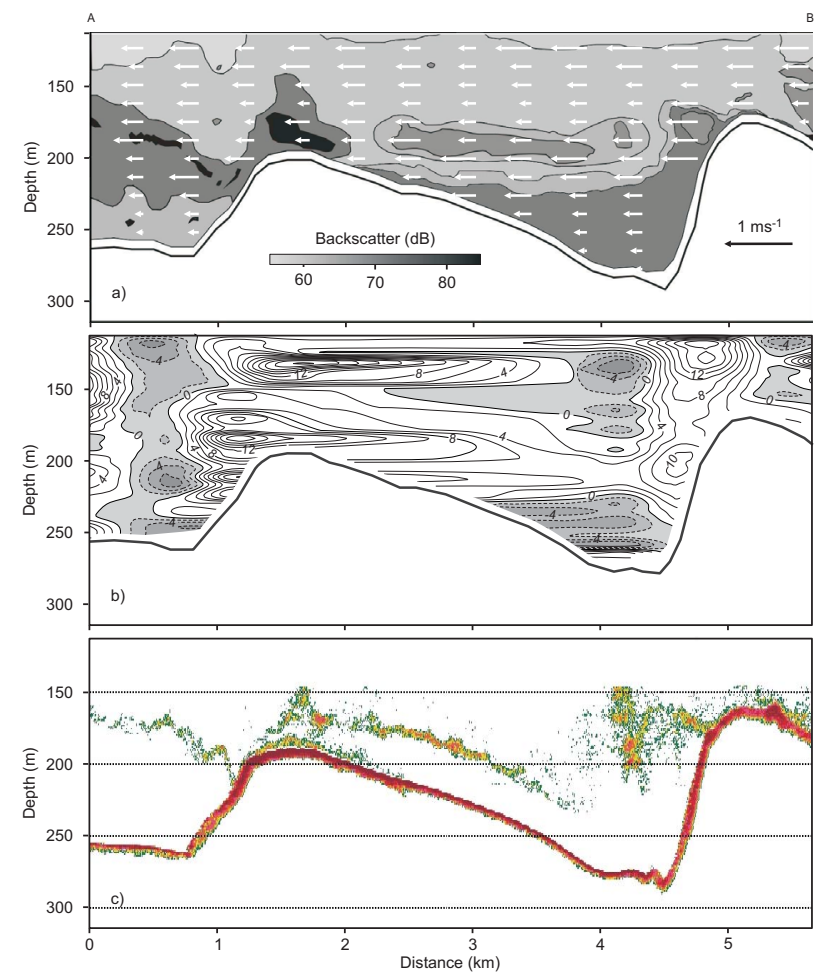

Figure 2. (a) The intensity contours from the backscatter (zooplankton biovolumes) in $\mathrm{dB}$ and current velocities arrows during ebb; (b) The transversal velocities in $\mathrm{cm} \cdot \mathrm{s}^{-1} \mathrm{ob}-$ tained from the $150 \mathrm{kHz}$ ADCP during ebb; and (c) The echo-sounder observations. The heavy black line in $a$ and $b$ represents the bottom and the grey zone represent zooplankton.

$$
\frac{1}{\rho_{0}} \frac{\partial p}{\partial \sigma}-\frac{g}{\rho_{0}} Z \rho=0
$$

where $u, v$ and $w$ are water velocities in the $x, y$ and $\sigma$ coordinate, respectively. $Z$ is the vertical stretching factor. $f$ is the Coriolis parameter. $P$ is the pressure. $\rho$ and $\rho_{0}$ are the total density and the mean average density (reference density). $g$ is the acceleration due to gravity. $v$ is the molecular viscosity. The bars represent the time average of the turbulent fluctuations. The continuity equation used in the model is:

$$
\frac{\partial \xi}{\partial t}+\frac{\partial u Z}{\partial x}+\frac{\partial v Z}{\partial y}+\frac{\partial w Z}{\partial \sigma}=0
$$

where $\xi$ is the averaged free surface elevation. Finally the transport of salt or any tracer is given by:

$$
\begin{aligned}
& \frac{\partial Z S}{\partial t}+\frac{\partial u Z S}{\partial x}+v \frac{\partial v Z S}{\partial y}+\frac{\partial w Z S}{\partial \sigma} \\
& =--\frac{\partial}{\partial \sigma}\left(s^{\prime} w^{\prime}-\frac{v}{Z} \frac{\partial S}{\partial \sigma}\right)+S_{\text {source } / \sin k}
\end{aligned}
$$

where $S$ is the tracer used in this study such as salt or suspended material. 


\section{Results and Discussion}

\subsection{Underway Transects}

The 150-kHz ADCP and EA 600 echo-sounder observations showed a clear wave signal pattern during ebb tide at a distance $<1.5 \mathrm{~km}$ from the starting point $\mathrm{A}$ of the transect (Figure 2), as indicated by the backscatter intensity (contours in Figure 2(a)) and echo-sounder (Figure 2(c)) data. The contours of the backscatter intensity and the echo-sounder signal suggest an adjustment of the isopycnal to bathymetry on the leeward side of the slope [30]. The depth of the backscatter intensity from the ADCP and the depth of the maximum values of the backscatter intensity from the echo-sounder were highly correlated among them during transect samplings (correlation value of 0.87 ). The isopycnal adjustment to bathymetry increased the near-bottom flow at the slope, as depicted by the current velocities (arrows) during ebbs (Figure 2(a)). The along-transect flow showed a deceleration of the upper-layer flow (at $200 \mathrm{~m}$ depth near $\mathrm{km}$ 0.7 and at $175 \mathrm{~m}$ depth at $4.4 \mathrm{~km}$ in Figure 2(a), the velocity changed from 0.5 to $0.25 \mathrm{~m} \cdot \mathrm{s}^{-1}$ ), where the back-scatter intensity suggested a vertical increment of the water surface with the same density; this scenario is also consistent with higher transversal velocities (Figure 2(b)). In turn, the near-bottom flow showed an acceleration, where a decrement of the water level with the same density was observed (140 - $190 \mathrm{~m}$ depth). The backscatter intensity signal from the ADCP and the echosounder also provide evidence of internal waves at the pycnocline interface and over the sills.

As the flow moved from the first sill toward the second sill (from km 4.5 to 2 in Figure 2(a)), the near-bottom flow (at $225 \mathrm{~m}$ depth) decelerated (changes in velocity from 0.6 to $0.2 \mathrm{~m} \cdot \mathrm{s}^{-1}$ ) due to mass conservation. However, the mid-depth flow ( $200 \mathrm{~m}$ depth) exhibited areas where the flow accelerated and other areas where it decelerated at the same depth, suggesting wave patterns. Such patterns were previously suggested by the echosounder and backscatter intensity data. Therefore, lee waves generated over the continental slope near Carmen Island should enhance nutrient exchange within the water column when internal waves break, thus producing mixing and making this an area of high biological productivity.

Previous studies related zooplankton abundance to high echo-sounder and backscatter intensity signals [31]. The observed zooplankton distribution over the water column and the water accelerations (changes from low to high velocities at the same depth) were further evidence of the presence of lee waves over the slope during ebb (Figure 2). Near the beginning of the slope transect, the flow decelerated at mid-depths and near the bottom (Figure 2(a)) when compared to the end of the transect (point B in Figure 2). This was due to bottom friction and perhaps to tidal phase, as the two ends of the transect were out of phase by approximately $0.41 \mathrm{~h}$. However, the mid-depth flow at the end of the transect, where the slope starts to increase sharply, accelerated. This was due to the hydraulic jump and the subsequent formation of lee waves at this location (Figure 2), which constrained the bottom flow to a smaller area, thereby increasing its velocity because of mass conservation. At mid-transect between the sills, the more homogeneous flow (between $\mathrm{km} 2.5$ to 4.5 in Figure 2) (i.e., relatively low vertical shear of the horizontal velocity $(\partial u / \partial z))$ when compared to the transect ends diminished lee wave formation. The Brunt-Väisälä frequency, calculated using the density values obtained from the CTD (Figure 3) at station + (Figure 1), showed a maximum value near $90 \mathrm{~m}$ depth, while at station A (Figure 3) the maximum value was observed at $160 \mathrm{~m}$ depth.

The relaxation of the flow and the lee waves produced a large zooplankton concentration over the water column (at $\mathrm{km} 1.8$ and 4.2 from the starting point in Figure 2) where the internal waves broke. The pycnocline suggested by the backscatter intensity at the slope (from km 2 to 3.5 in Figure 2) showed a more stable pattern, and the wave pattern observed at the transect ends was lacking since they were no longer under the influence of the sills. Therefore, the areas of high biological productivity observed near Carmen Island [32] (Figure 1) could be related to lee wave activity that mainly was produced

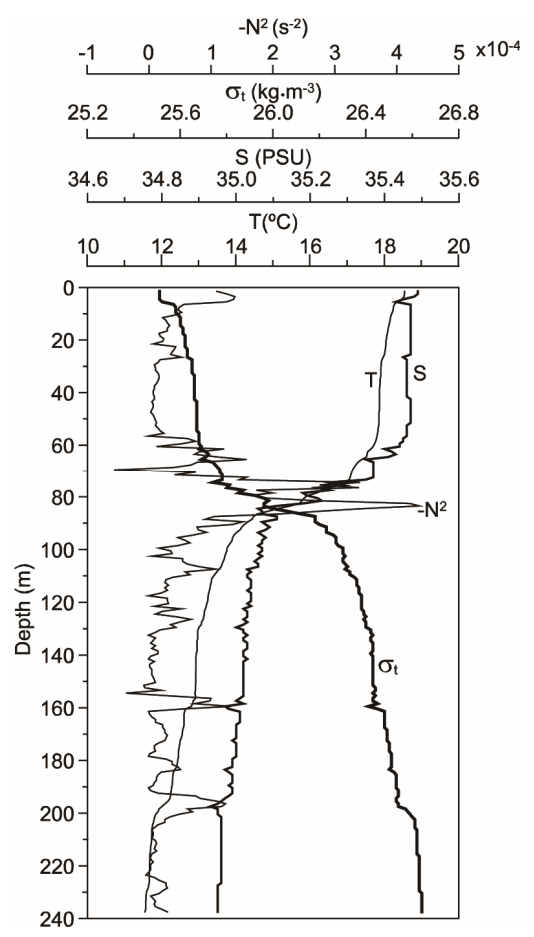

Figure 3. CTD profiles and the Brunt-Väisälä frequency at station + on February 27, 2006. 
when internal waves broke. The vertical displacement of zooplankton, nutrients, and detritus from close to $170 \mathrm{~m}$ depth to near the sea surface has a major ecological impact within the area. Turbulence is usually related to nutrient flux and to nutrient suspension within the water column [32]. When internal wave break the turbulence of the water increase, therefore turbulence could be one of the reason for the high surface biological productivity observed near Carmen Island, owing to wave activity.

The backscatter intensity data suggest that surface water was constricted to a smaller area over the sills during ebb tide periods due to internal wave activity, and this would have pumped zooplankton and nutrients to the near-surface waters. However, the high productivity area concentrated near the surface during maximum ebb should have moved back to its original depth at the end of the ebb once the flow relaxed due to buoyancy stability.

\subsection{Velocity Time Series, the Absolute Acoustic Intensity, and Zooplankton}

Figure 4 shows the ebb tide period depicted with a time series of velocity contours (Figure 4). The time-series velocity measurements were taken where the slope starts to increase sharply at a distance of $4 \mathrm{~km}$ from the transect observations (@ in Figure 1). At this location, the sinusoidal shape in Figure 4 represents the ebb tide period when the lee waves were observed.

The absolute acoustic intensity $(\mathrm{dB})$ obtained from the backscatter intensity of the $150-\mathrm{kHz}$ ADCP was significantly correlated with zooplankton biomass dry weight $\left(\mathrm{mg} \cdot \mathrm{m}^{-3}\right.$ ) (correlation of $0.64, \mathrm{p}<0.01$ ) (Figure 5), the linear regression explained $\sim 70 \%$ of the variability. Thus, the backscatter of the ADCP can be almost directly related with the zooplankton dry weight biomass. The zooplankton community was represented by 24 major groups; the five main groups in terms of percent abundance were cladocera (44.05\%), copepoda (23.13\%), siphonophora (8.42\%), chaetognatha $(7.69 \%)$, and crustacean larvae (3.86\%) (Table 1). This is important since more than $86 \%$ of zooplankton organisms had a hard structure. The backscatter intensity signal obtained with the ADCP in areas with hard zooplankton structure organisms provides accurate and confinable data. If the same percentage were formed by jelly organisms the backscatter intensity error will be greater and it would be hard to calculate the biovolumes owing to the attenuation of the signal produced by jelly organisms.

Finally a spectral analysis using a Fourier transform method combined with the boundary conditions obtained from the ADCP and with tidal amplitude and phase obtained from Salas-de-Leon et al. [18] and Carbajal and Backhaus [28] were used to run a model in order to simulate the hydraulic jump. Accordingly to the Fourier

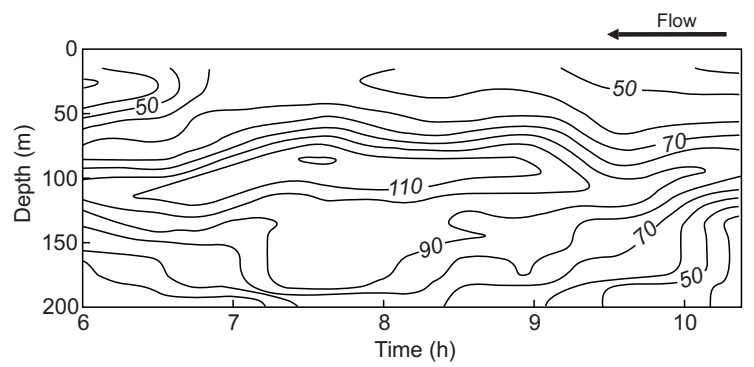

Figure 4. Velocity contours $\left(\mathrm{cm} \cdot \mathrm{s}^{-1}\right)$ at station @ on February 27,2006 . Positive values indicate seaward (southwestward) currents.

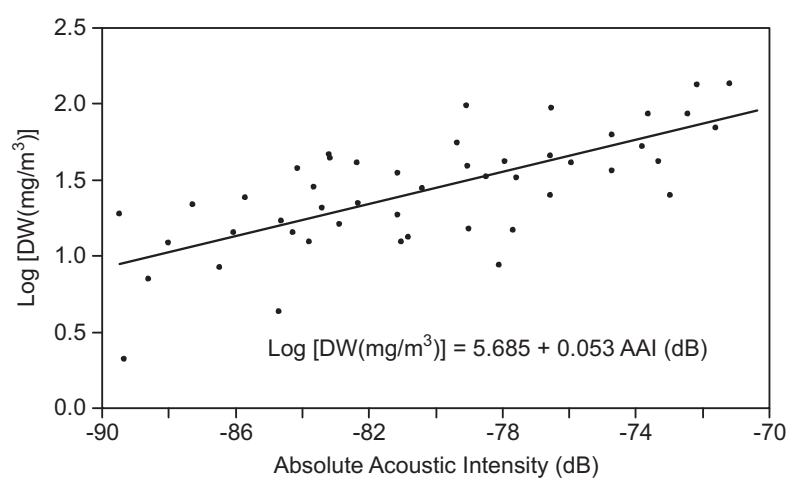

Figure 5. Correlation between the absolute acoustic intensity (dB) and log of the dry weight of zooplankton biomass $\left(\mathrm{mg} \cdot \mathrm{m}^{-3}\right)$ for the "El Puma" R/V $150 \mathrm{kHz}$ ADCP.

Table 1. Percentage abundance of zooplankton groups collected with the $505 \mu \mathrm{m}$ net.

\begin{tabular}{ll}
\hline 1. Cladocera (44.05\%) & 13. Mysidacea $(0.64 \%)$ \\
2. Copepoda (23.13\%) & 14. Polychaeta $(0.57 \%)$ \\
3. Siphonophora (8.42\%) & 15. Icthyoplankton (0.41\%) \\
4. Chaetognata (7.69\%) & 16. Cirripedia $(0.39 \%)$ \\
5. Larvaecrustacean (3.86\%) & 17. Hydrozoa $(0.34 \%)$ \\
6. Salpida (2.23\%) & 18. Heteropoda (0.22\%) \\
7. Euphausiacea (2.12\%) & 19. Asteroidea (0.17\%) \\
8. Pteropoda (2.61\%) & 20. Decapoda: Penaeoidea (0.17\%) \\
9. Ostrcoda (1\%) & 21. Amphipoda $(0.14 \%)$ \\
10. Foraminifera $(0.93 \%)$ & 22. Ctenophora $(0.04 \%)$ \\
11. Appendicularia (0.78\%) & 23. Doliolida $(0.03 \%)$ \\
12. Scyphomedusae (0.67\%) & 24. Cephalopoda (0.01\%) \\
\hline
\end{tabular}

analysis (Figure 6) and the in-situ observations the hydraulic jump was observed during ebb tide period under specific conditions such as the intensification of the along slope current. The intensification of the current was attributed to advective processes such as remote winds [30] and possibly to the cyclonic circulation observed along the Gulf of California [33].

\subsection{Model Outputs}

Model outputs from the ROMS were also used to de- 


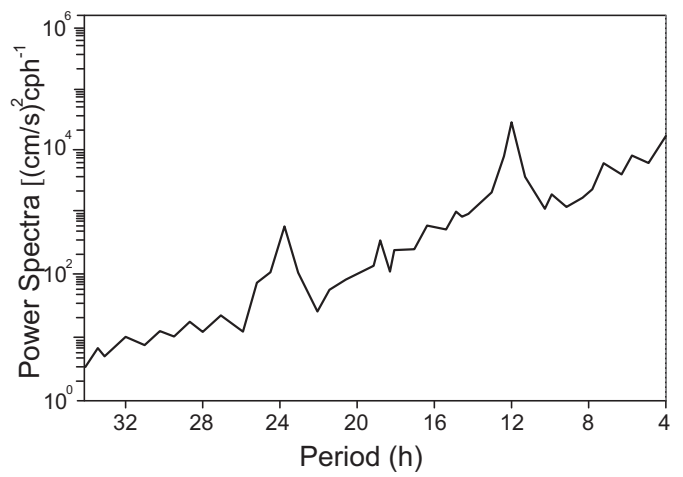

Figure 6. Period $(1 / f)$ spectra of the current velocity $\left(U=\sqrt{u^{2}+v^{2}}\right)$ at station @ of Figure 1.

scribe the dynamics of an idealized generic system similar to the one located near Carmen Island (Figure 7). The model outputs showed lee wave formation where the slope starts to increase sharply (down-slope). Model outputs during ebb tide periods without the influence of Coriolis acceleration $(f=0)$ (Figures 7(a) and (c)) showed a hydraulic jump over the slope (i.e., the flow changed from supercritical to subcritical). The pycnocline (represented by contours in Figure 7) showed an adjustment to bathymetry, the near-bottom flow was constrained to a smaller area. The seaward flow near the bottom accelerated due to mass conservation. The near-surface flow, in turn, decelerated because the same amount of water had to pass through a bigger area per width unit. Without considering Coriolis acceleration, lateral displacement of any tracer located at the pycnocline depth was displaced toward the sides from the slope location (Figure 8) due to horizontal velocity gradients $(\partial v / \partial x \neq \partial u / \partial y \neq 0): u$ and $v$ are water velocities in the $x$ and $y$ direction, aligned in the along and across-slope direction, respectively. According to this equation, a simulation with (Figures 8(b) and (d)) and without (Figures 8(a) and (c)) Coriolis acceleration was used to estimate the depth (in sigma coordinates) at which a given particle released at sigma equal 1 over the right boundary of the domain would be found after $26 \mathrm{~h}$ of simulation (Figures 8(a) and (b)), after the model reached stability. In the simulations in which $|-f v| \neq 0$, the particles were displaced toward the right side of the modelled region, which is equivalent to being displaced toward Carmen Island in the real case. This result suggests that an area of high productivity exists near Carmen Island. The number of times those particles will pass by each grid point during the $26 \mathrm{~h}$ simulation (Figures 8(c) and (d)) also showed asymmetry for the simulated case where $|-f v| \neq 0$. Which implies that a given particle released at sigma equal 1 over the right boundary of the domain would pass a higher number of times toward the right side of the domain, after $26 \mathrm{~h}$ of simulation, when $|-f v| \neq 0$ (Figures 8(d) and (c)).

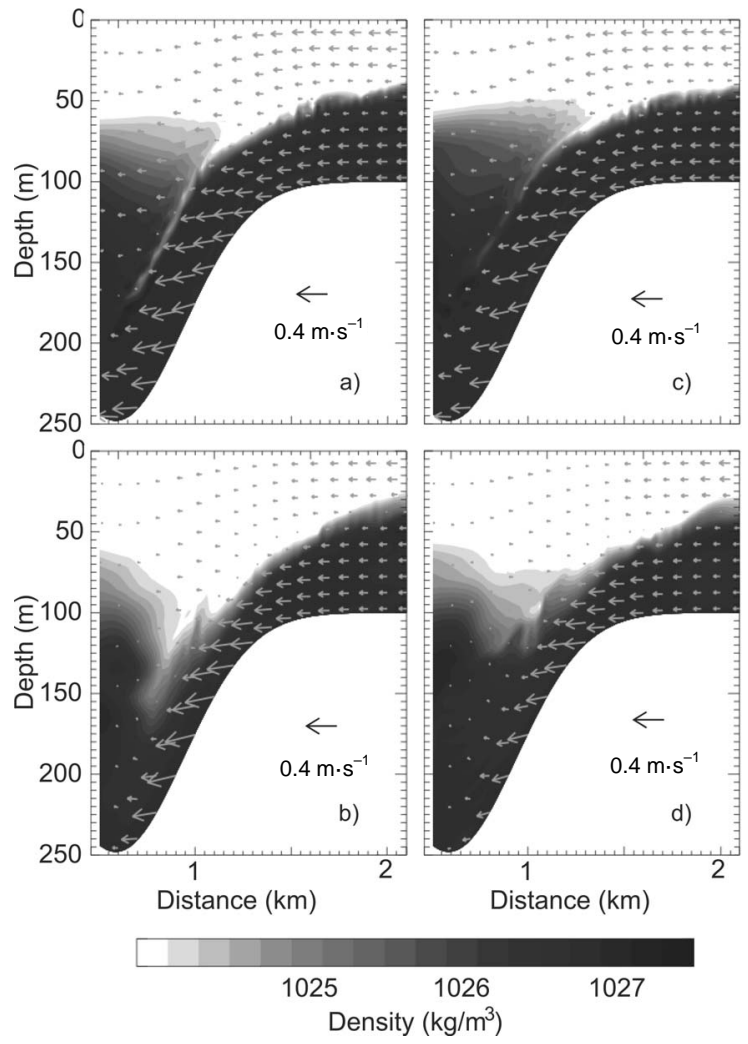

Figure 7. Model outputs during ebb tide periods without the influence of Coriolis acceleration $(f=0)$ at (a) $t=4.2$ and (c) $t=4.4$ days and during ebb tide periods with the influence of Coriolis acceleration at (b) $t=4.2$ and (d) $t=4.4$ days.

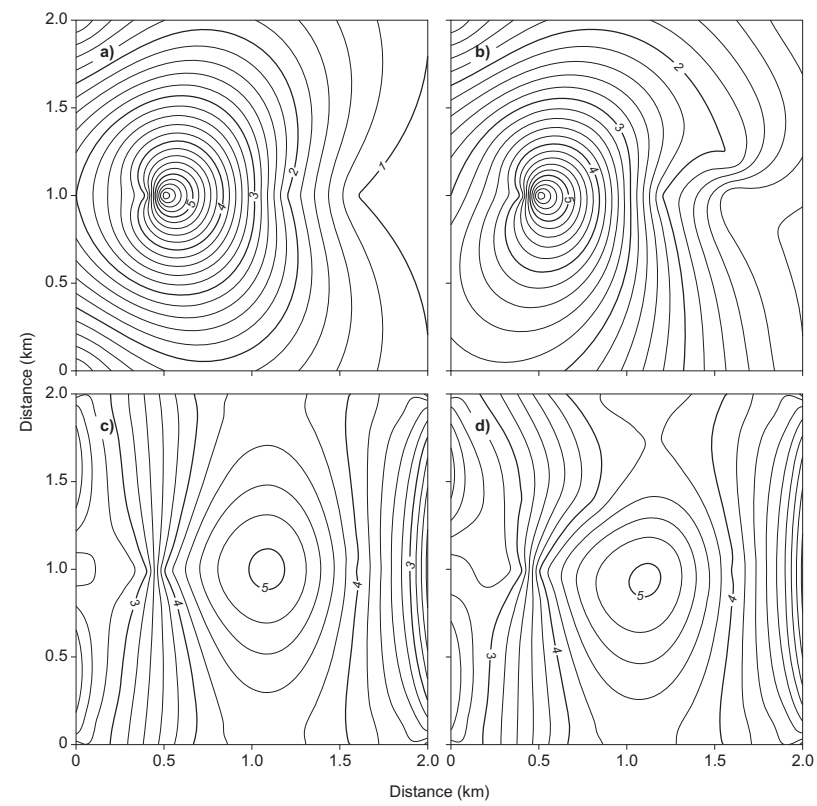

Figure 8. Depth in sigma coordinates of a given particle released at sigma $=1$ over the right boundary of the domain after $26 \mathrm{~h}$ of simulation with (b) and without (a) Coriolis acceleration and the number of times those particles will pass by each grid point during the $26 \mathrm{~h}$ with (d) and without (c) Coriolis acceleration. 
At the pycnocline interface (Figure 7) a clear wave signal was observed, as previously described based on observations. Because the observed zooplankton patches were assumed to be located at the pycnocline depth due to buoyancy stability, they also should follow a wave pattern. The pycnocline strength from the model outputs was determined by salinity. The temporal variability of salinity $(\Delta s=5)$ produced a density variation of $4 \mathrm{~kg}$ $\mathrm{m}^{-3}$, whereas the temporal variability of temperature $(\Delta t=3 \mathrm{C})$ produced a density variation of $0.6 \mathrm{~kg} \cdot \mathrm{m}^{-3}$. Under such simulations, zooplankton should mostly concentrate at the halocline depth, which is located at the same depth as the pycnocline and thermocline (Figure 3). Therefore, zooplankton were assumed to move downward following the slope and then upward, following a wave pattern as the flow moved seaward (Figure 7).

Once the Coriolis parameter $(f)$ was set to $2 \omega \sin$ (latitude), where $\omega$ is the angular velocity of the Earth $\left(7.27 \times 10^{-5} \mathrm{~s}^{-1}\right)$, the Coriolis acceleration value $\left(0.73 \times 10^{-4} \mathrm{~m} \cdot \mathrm{s}^{-2}\right)$ was close to the along-slope advective acceleration term $\left(1.2 \times 10^{-4} \mathrm{~m} \cdot \mathrm{s}^{-2}\right)$ (Figures 7(b) and (d)), calculated at the pycnocline depth where zooplankton should concentrate. Therefore, vertical zooplankton concentration over the continental slope should not be as marked as for the case in which $|-f v|=0$ because some of the zooplankton located over the main slope axis were dispersed horizontally ( $y$ direction) (Figures 6(a) and (c)). Zooplankton displacement was not only attributed to Coriolis acceleration. Horizontal displacement was mainly produced by horizontal velocity shear $(\partial v / \partial x \neq 0)$, i.e. the cross-advective acceleration term $(80.8 \%$ of horizontal zooplankton displacement). However, Coriolis acceleration deflects zooplankton concentration toward Carmen Island (19.2\% of horizontal zooplankton displacement), making it an area of high biological productivity compared to the surrounding waters [32]. Data observations and satellite images also showed a high biological productivity area near Carmen Island [34], which confirmed model simulations. Thus, when internal waves break, zooplankton concentration is displaced within the water column and toward the sides due to horizontal velocity shear and Coriolis acceleration. Assuming zooplankton to be a passive tracer and assuming it moves with the water, the only mechanisms that will move it toward the sides will be by advection and Coriolis acceleration, as both terms include lateral water flow.

When Coriolis acceleration was added to the simulations $|u \partial u / \partial x| \geq|-f v|$ (Figure 9), the pycnocline also adjusted to bathymetry, accelerating the constrained along-slope flow near the bottom (Figure 7). In the along-slope momentum equation, the cross-slope advective term $(v \partial u / \partial y)$ increased when compared to the previous case without Coriolis acceleration. This condition dispersed zooplankton across the slope (in the $y$ di-

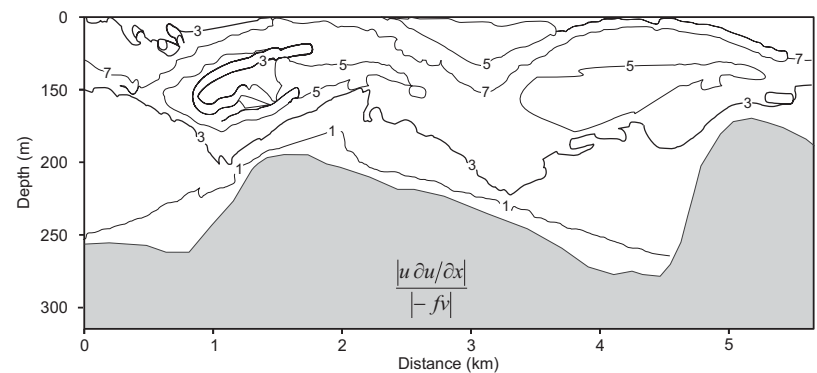

Figure 9. Contours of the horizontal advective acceleration term versus Coriolis acceleration $|u \partial u / \partial x| /|-f v|$ on February $27,2006$.

rection) by more than $15 \%$ of the total concentration, reducing the vertical concentration of zooplankton usually observed over the main axis of irregular bathymetries where $\partial u / \partial y \approx 0$ The lateral displacement of zooplankton was mainly assumed to be related to the horizontal advective acceleration term, whereas the asymmetrical, high productivity area near Carmen Island (northward) compared to surrounding waters (southward) was attributed to Coriolis acceleration.

\section{Conclusions}

Rapid changes in zooplankton concentration can be due to rapid population growth or to the redistribution or redispersion of a stable population. This paper deals with internal waves as a physical factor implicated in redistribution or redispersion of zooplankton population.

ADCP and water density profiles were measured over a $280 \mathrm{~m}$ deep slope to elucidate the effect of the irregular bathymetry on zooplankton distribution. These measurements were combined with velocity and density simulations from the ROMS with and without the influence of Coriolis acceleration. Measurements showed an acceleration of the near-bottom flow and a deceleration of the near-surface flow as it moved toward increasing depths. The acceleration of the near-bottom flow as it moved toward increasing depths was produced by the adjustment of the isopycnals to bathymetry (hydraulic jump). Zooplankton concentrations were located near the pycnocline interface due to buoyancy stability, moved downward at the slope due to the hydraulic jump, and then moved upward, thereby exhibiting wave patterns. The high productivity area observed near Carmen Island was caused by nutrient pumping created by internal waves features produced by the slope.

Model outputs without the influence of Coriolis acceleration described a scenario similar to that based on observations over the slope. The cross-slope advective term in the along-momentum equation dispersed zooplankton across the slope. However, when Coriolis acceleration was added to the along-slope momentum equation, the 
lateral flow increased by $19.2 \%$. Therefore, Coriolis acceleration deflected zooplankton concentration toward Carmen Island. Thus, the vertical zooplankton concentration usually observed over the main axis of irregular bathymetries, such as slopes, was reduced for relatively high values of the Coriolis acceleration term $(U / f l \leq 1)$ in the momentum equation, as was the case for the system in the Gulf of California.

\section{Acknowledgements}

This study was supported financially by the "Instituto de Ciencias del Mar y Limnología" of the Universidad Nacional Autónoma de México (UNAM). We would like to thank the "El Puma" crew and officers who helped during different stages of data collection. Jorge Castro improved the figures in this manuscript. The anonymous reviewers improved the quality of the manuscript with their suggestions and comments.

\section{REFERENCES}

[1] H. Stommel and H. G. Farmer, "Abrupt Change in Width in Two Layer Open Channel Flow,” Journal of Marine Research, Vol. 11, 1952, pp. 205-214.

[2] D. M. Farmer and L. Armi, "Maximal Two-Layer Exchange over a Sill and through the Combination of a Sill and a Contraction with Barotropic Flow," Journal of Fluid Mechanics, Vol. 164, 1986, pp. 53-76. doi:10.1017/S002211208600246X

[3] C. E. Lennert-Cody and P. J. S. Franks, "Plankton Patchiness in High-Frequency Internal Waves," Marine Ecology Progress Series, Vol. 186, 1999, pp. 59-66. doi:10.3354/meps186059

[4] A. Genin, "Bio-Physical Coupling in the Formation of Zooplankton and Fish Aggregations over Abrupt Topographies," Journal of Marine Systems, Vol. 50, 2004, pp. 3-20. doi:10.1016/j.jmarsys.2003.10.008

[5] D. A. Salas-de-Leon, M. A. Monreal-Gomez, M. Signoret and J. Aldeco, "Anticyclonic-Cyclonic Eddies and Their Impact on Near-Surface Chlorophyll Stocks and Oxygen Supersaturation over the Campeche Canyon, Gulf of Mexico," Journal of Geophysical Research, Vol. 109, 2004, Article ID: C05012. doi:10.1029/2002JC001614

[6] L. Zavala-Sansón and A. Provenzale, "The Effects of Abrupt Topography on Plankton Dynamics,” Theoretical Population Biology, Vol. 76, No. 4, 2009, pp. 258-267. doi:10.1016/j.tpb.2009.08.004

[7] J. P. Ryan, M. A. McManus and J. M. Sullivan, "Interacting Physical, Chemical and Biological Forcing of Phytoplankton Thin-Layer Variability in Monterey Bay, California," Continental Shelf Research, Vol. 30, No. 1, 2010, pp. 7-16.

[8] D. M. Farmer and J. D. Smith, “Tidal Interaction of Stratified Flow with a Sill in Knight Inlet," Deep Sea Research Part A, Vol. 27, No. 4, 1980, pp. 239-254. doi:10.1016/0198-0149(80)90015-1
[9] W. M. Graham, P. Fransesc and W. M. Hamner, “A Physical Context for Gelatinous Zooplankton Aggregation: A Review,” Hydrobiology, Vol. 451, 2001, pp. 199212. doi:10.1023/A:1011876004427

[10] J. D. Nash, E. Kunze, J. M. Toole and R. W. Schmitt, "Internal Tide Reflection and Turbulent Mixing on the Continental Slope,” Journal of Physical Oceanography, Vol. 34, No. 5, 2003, pp. 1117-1134.

[11] A. Valle-Levinson, A. Trasvina-Castro, G. Gutierrez de Velasco and R. G. Armas, "Diurnal Vertical Motions over a Seamount of the Southern Gulf of California," Journal of Marine Systems, Vol. 50, No. 1, 2004, pp. 61-77.

[12] R. E. Shea and W. W. Broenkow, “The Role of Internal Tides in the Nutrient Enrichment of Monterey Bay, California," Estuarine, Coastal and Shelf Science, Vol. 15, 1982, pp. 57-66. doi:10.1016/0272-7714(82)90036-1

[13] J. M. Klymak and M. C. Gregg, “Tidally Generated Turbulence over the Knight Inlet Sill," Journal of Physical Oceanography, Vol. 34, No. 5, 2004, pp. 1135-1151.

[14] P. Sangrà, G. Basterretxea, J. L. Pelegrí and J. Aristegui, "Chlorophyll Enhancement By Internal Waves in the Shelf-Break of Gran Canaria (Canary Islands),” Scientia Marina, Vol. 65 No. 1, 2001, pp. 89-97.

[15] K. Rinke, I. Hübner, T. Petzoldt, S. Rplinski, M. KönigRinke, J. Post, A. Lorke and J. Benndorf, "How Internal Waves Influence the Vertical Distribution of Zooplankton,” Freshwater Biology, Vol. 52, No. 1, 2007, pp. 137 144.

[16] P. J. S. Franks, "Spatial Patterns in Dense Algal Blooms," Limnology and Oceanography, Vol. 42, No. 5, 1997, pp. 1297-1305.

[17] B. R. Eden, D. K. Steinberg, S. A. Goldthwait and D. J. McGillicuddy Jr., "Zooplankton Community Structure in a Cyclonic and Mode-Water Eddy in the Sargasso Sea," Deep Sea Research Part A, Vol. 56 No. 10, 2009, pp. 1757-1776. doi:10.1016/j.dsr.2009.05.005

[18] D. A. Salas-de-Leon, N. Carbajal-Perez, M. A. MonrealGomez and G. Barrientos-MacGregor, "Residual Circulation and Tidal Stress in the Gulf of California," Journal of Geophysical Research, Vol. 108, No. 10, 2003, p. 3317.

[19] P. Ladrón-de-Guevara-Porras, E. B. E. Lavaniegos and D. G. Heckel, "Fin Whales (Balaenoptera physalus) Foraging on Daytime Surface Swarms of the Euphausiid Nyctiphanes simplex in the Ballenas Channel, Gulf of California, Mexico,” Journal of Mammalogy, Vol. 89, No. 3, 2008, pp. 559-566.

[20] D. Salas-Monreal and A. Valle-Levinson, "Continuously Stratified Flow Dynamics over a Hollow," Journal of Geophysical Research, Vol. 114, 2009, Article ID: C03021. doi:10.1029/2007JC004648

[21] C. L. Trump and G. Marmorino, "Calibration a Gyrocompass Using ADCP and DGPS Data," Journal of Atmospheric and Oceanic Technology, Vol. 14, No. 1, 1997, pp. 211-214.

[22] A. R. Longhurst and D. L. R. Seibert, "Skill in the Use of Folsom's Plankton Sampler Splitter,” Limn Ocean, Vol. 12, No. 2, 1967, pp. 334-335. doi:10.4319/lo.1967.12.2.0334 
[23] G. Tregouboff and Rose, "Manuel de Planctonologie Mediterraneenne,” Tome II. Centre National de la Recherche Scientifique, Paris, 1957.

[24] R. Robertson, "Modeling Internal Tides over Fieberling Guyot: Resolution, Parameterization, Performance,” Ocean Dynamics, Vol. 56, No. 5-6, 2006, pp. 430-444.

[25] A. F. Shchepetkin and J. C. McWilliams, "A Method for Computing Horizontal Pressure-Gradient Force in an Oceanic Model with a Nonaligned Vertical Coordinate,” Journal of Geophysical Research, Vol. 108, No. C3, 2003, p. 3090. doi:10.1029/2001JC001047

[26] A. M. Moore, H. G. Arango, E. Di Lorenzon, B. D. Cornuelle, A. J. Miller and D. J. Neilson, “A Comprehensive Ocean Prediction and Analysis System Based on the Tangent Linear and Adjoint of a Regional Ocean Model," Ocean-Modeling, Vol. 7, No. 2, 2004, pp. 227-258. doi:10.1016/j.ocemod.2003.11.001

[27] M. A. Monreal-Gomez and D. A. Salas-de-León, "Simulación de la Circulación en la Bahía de Campeche," Geofisica Internacional, Vol. 29, 1990, pp. 101-111.

[28] N. Carbajal and J. O. Backhaus, "Simulation of Tides, Residual Flow and Energy Budget in the Gulf of California," Oceanologica Acta, Vol. 21, No. 3, 1998, pp. 429446. doi:10.1016/S0399-1784(98)80028-5

[29] L. Y. Oey, T. Ezer, Y. Miyazawa and C. R. Wu, "Edito-
rial-International Workshop on Modeling the Ocean (IWMO) Special Issue in Ocean Dynamics," Ocean Dynamics, Vol. 60, 2010, pp. 299-300. doi:10.1007/s10236-010-0281-7

[30] D. Salas-Monreal, "Continuously Stratified Flow Dynamics over a Hollow,” Ph.D. Thesis, Old Dominion University, Norfolk, 2006, 88 p.

[31] K. J. Heywood, "Diel Vertical Migration of Zooplankton In the Northeast Atlantic,” Journal of Plankton Research, Vol. 18, No. 2, 1996, pp. 163-184. doi:10.1093/plankt/18.2.163

[32] D. A. Salas-de-León, N. Carbajal, M. A. Monreal-Gómez and A. Gil-Zurita, "Vorticity and Mixing Induced by the Barotropic $\mathrm{M}_{2}$ Tidal Current and Zooplankton Biomass Distribution in the Gulf of California,” Journal of Sea Research, Vol. 66, 2, 2011, pp. 143-153.

[33] W. S. Pegau, E. Boss and A. Martinez, "Ocean Color Observations of Eddies during the Summer in the Gulf of California,” Geophysical Research Letters, Vol. 29, No. 9, 2002, p. 1295. doi:10.1029/2001GL014076

[34] A. E. White, F. G. Prahl and R. M. Letelier, "Summer Surface Waters in the Gulf of California: Prime Habitat for Biological $\mathrm{N}_{2}$ Fixation," College of Oceanic and Atmospheric Sciences, Oregon State University, Corvallis, 2007. 